\title{
ABSTRACTS
}

(This section of the JoURNAL is published in collaboration with the two abstracting Journals, Abstracts of World Medicine, and Abstracts of World Surs section of the JOURNAL is published in collaboration with the two abstracting Journals, Abstracts of World Medicine, and Abstracts of World toxicology ; industrial physialogy ; industrial lung disease; industrial skindiseases; accidents and orthopaedic surgery ; industrial ophthalmology; toxicology ; industrial physialogy ; industrial lung disease ; industrial skindiseases; accidents and orthopaedic surgery
environment; general. Not all sections will necessarily be represented in any one issue)

\section{INDUSTRIAL TOXICOLOGY}

Effects of Dimethyl and Diethyl paraNitrophenyl Thiophosphate on Experimental Animals. DIECHMANN, W. B., Pugliese, W., and Cassidy, J. (1952). Arch. industr. Hyg. occup. Med., 5, 44.

Both the diethyl and dimethyl esters of thiophosphoric acid are now extensively used as insecticides. The former was known to have an effect similar to that of drugs having a cholinergic action. The possible toxicity of the dimethyl derivative was therefore investigated. It is concluded that the safety measures required in the use of parathion (diethyl p-nitrophenyl thiophosphate) should be applied with equal vigour in the use of dimethyl $p$ nitrophenyl thiophosphate, although the latter compound is less toxic by one-fifth to one-half than parathion.

M. A. Dobbin Crawford.

Physiological Response of Experimental Animals to the Vapor of 2-Nitropropane. TrEON, J. F., and DuTRA, F. R. (1952). Arch. industr. Hyg. occup. Med., 5, 52.

The hazards attending the use of 2-nitropropane, a nitroparaffin used as a commercial solvent, were investigated in experimental animals. Cats, rats, rabbits, and guinea-pigs, in that order, were found decreasingly susceptible to intoxication by the vapour. All survived repeated 7-hour exposures to an atmosphere containing 2-nitropropane in a concentration of $0.297 \mathrm{mg}$. per litre, or 83 parts per million (p.p.m.), the animals being exposed on 5 days a week for 26 weeks. All the animals except the cats survived similar exposure to an atmosphere containing 328 p.p.m. The minimum lethal dose for cats was 1 hour's exposure to 2,353 p.p.m., or $2 \cdot 25$ hours' exposure to 1,148 p.p.m., or $4 \cdot 5$ hours' exposure to 714 p.p.m.

Lethargy and feebleness developed, proceeding to a state of prostration with dyspnoea, cyanosis, occasional convulsions, and ending in coma and death. Lacrimation, salivation, and gastric regurgitation were noted in cats only. Those animals surviving for some hours lost weight, methaemoglobin and Heinz bodies were formed in the blood, and the clotting time was prolonged. Cats dying after several repeated exposures to a concentration of 328 p.p.m. showed severe parenchymal degeneration and focal necrosis of the liver, with a moderate or slight toxic degeneration of the heart and the kidneys; there were also haemorrhages into the alveoli of the lungs with oedema of the lung tissues and interstitial pneumonitis. Severe acute poisoning caused general injury to the endothelium of the blood vessels throughout the body, with pulmonary haemorrhage, selective disintegration of the neurones of the brain, and liver damage.

A concentration of $0.18 \mathrm{mg}$. per litre (50 p.p.m.) is suggested as the maximum allowable for a working day. [This agrees with the ruling of the American Conference of Governmental Industrial Hygienists, but is double that recommended by other authorities.]

\section{A. Dobbin Crawford.}

Toxicity of Sulfuric Acid Mist to Guinea Pigs. AMDUR, M. O., Schulz, R. Z., and Drinker, P. (1952). Arch. industr. Hyg. occup. Med., 5, 318.

A quantitative study was made at Harvard University School of Public Health of the toxicity of low concentrations of sulphuric acid mist to guinea-pigs. The period of exposure varied between 8 and 72 hours, and the concentration of acid between $8 \mathrm{mg}$. and over $50 \mathrm{mg}$. per cubic metre; the mean particle size was $1 \mu$. Full details are given of the apparatus used to produce the mist [for which the original should be consulted]. Concentrations up to $0.24 \mathrm{mg}$. per cubic metre have been reported in the Los Angeles "smog" area and are to be expected occasionally in industrial communities burning soft coal. Guinea-pigs were used as they are more susceptible to sulphuric acid than other laboratory animals, two groups, of different ages, being studied separately. All the animals survived a concentration of $8 \mathrm{mg}$. per cubic metre. The LD50 for the older animals was $50 \mathrm{mg}$. per cubic metre, for the younger animals 18 mg. per cubic metre. It was found that sulphuric acid produces two distinct and different toxic actions. The animals which died almost all succumbed to laryngeal spasm. Those which survived the initial exposure were killed about 3 weeks later, when deep-seated lung damage was still present. The spasm-producing action depended on the concentration of acid and not on the length of exposure, whereas the extent of lung damage depended on the total exposure, that is, the product of concentration and time of exposure. Lung damage consisted of pneumonic changes, haemorrhages, thickening of the alveolar walls, atelectasis, and congestion of the alveolar spaces. It is concluded that inhalation of sulphuric acid in the concentrations used may produce more severe and lasting lung damage than has previously been thought. Leslie G. Norman. 
Hematological Investigation on Workers Exposed to Mercury Vapour. Kesic, V. B., and HaEusler, V. (1951). Industr. Med. and Surg., 20, 485.

Observation over a period of years in Yugoslavia of patients suffering from chronic mercurialism failed to disclose any noteworthy alterations in their blood elements or haemoglobin. Blood examinations were then undertaken, in Idria, on 130 mercury miners, on 59 workers employed in the mercury-smelting plant, and on 70 women workers in a felt-hat factory. To serve as a control 202 metal-industry workers and 264 women employed in the textile industry were also examined. No fewer than 71 of the mercury miners and smelters and 47 of the felt-hat workers showed frank symptoms of chronic mercury intoxication. The concentration of mercury vapour in the working atmosphere was high; in the mine it varied between 1.2 and $5.9 \mathrm{mg}$. per c. metre of air. (Maximum atmospheric concentration= $0.1 \mathrm{mg}$. per c. metre.) The results, which are presented in detail in tabular form, show no significant differences between the blood counts of the exposed workers and those of the control subjects. The estimation of haemoglobin, colorimetric and photometric, yielded less definite results, for the readings showed much variation. In a few of the exposed workers the readings were high -over $100^{\circ} \mathrm{o}$. It is pointed out that in relation to haemoglobin values there are many other factors which should be considered.

No conclusions can be drawn from these small numbers, but investigations are continuing.

[The bibliography contains a brief quotation from each author referred to.] M. A. Dobbin Crawford.

Eye Changes following Exposure to Metallic Mercury. LockeT, S., and NAZroO, I. A. (1952). Lancet, 1, 528.

Among 51 repairers of direct-current electric meters who handled metallic mercury and were examined for eye changes, 12 showed a matt-brown reflex from the anterior lens capsule. This change seems to depend mainly on length of exposure to metallic mercury, and is not related to symptoms of mercury intoxication at the time of examination. In all cases this brown reflex was bilateral and apparently had no effect on visual acuity. No evidence of retrobulbar neuritis was found in any of the 51 workers examined. It is suggested that this coloured reflex from the lens could be used as a screening device for atmospheric mercury levels.-(Authors' summary.)

\section{INDUSTRIAL LUNG DISEASES}

Tuberculosis in Anthracosilicosis. Theodos, P. A., and Gordon, B. Amer. Rev. Tuberc., 65, 24.

This is a study from Jefferson Medical College Hospital, Philadelphia, of 750 cases of anthracosilicosis occurring in anthracite miners in Pennsylvania. Of this number $12.9 \%$ had sputum positive for tubercle bacilli; the inclusion of cases with healed tuberculous lesions and cases suspected on clinical or radiological grounds but sputum-negative raised the total classified as anthracosilicosis with tuberculosis to $14.9 \%$. Tuberculosis was found most frequently in miners who had been exposed to dust for 20 to 40 years, the highest incidence $(75 \%)$ being in the fourth and fifth decades of life. It was eight times as common at age 35 to 44 , and three times as common at age 45 to 54 , as in a comparable group of workers in other industries.

The percentage incidence of symptoms and signs is given, and the radiological findings are discussed. Of 244 cases showing "conglomerate" opacities tuberculosis was diagnosed in only $11.5 \%$; of 320 cases showing asymmetrical shadows only $25.9 \%$ proved to be tuberculous. Only $25 \%$ of the cases showing deviation of the trachea proved to be tuberculous. Tuberculosis was found most commonly in association with third-stage silicosis. The question whether the tuberculosis studied was a reactivation of disease existing before exposure to silica or a new infection is discussed.

The life-expectation for cases treated at home was up to 3 years from time of diagnosis, and probably one year longer with hospital care. Tuberculosis occurring with nodular silicosis was thought to have a somewhat better prognosis than that occurring with massive fibrosis. The scope of treatment is limited, and is mainly symptomatic.

[It is not fully clear that the authors have appreciated that the relationship between anthracosilicosis and tuberculosis may be different from that between "pure" silicosis and tuberculosis.] L. W. Hale.

A Contribution to the Study of the Risk of Silicosis in Foundries. UYTDENHOEE, A. (1951). Arch. belges Méd. soc., 9, 357.

The author describes a study, made by the Medical Inspectorate of the Belgian Ministry of Labour, of the risk of contracting silicosis in iron and steel foundries. The various types of foundry work are described and the results given of dust counts made with an Owens jet dust counter in samples of air taken from different situations in a foundry. Dust extracted from the air and dust deposited in various parts of the foundry were also chemically analysed and in both cases were found to contain a considerable percentage of silica and iron. At the same time, 302 foundry workers from 58 different factories were examined radiologically, of whom 65 showed radiological evidence of silicotic fibrosis. In 47 of these cases there was accentuation of the lung markings with infrequent small nodules, in 17 generalized small nodules in addition, and in one definite nodulation. This last was in a man of 49 who had been a planer for 22 years. Most of the affected workmen were moulders, but a few were cupola men, grinders, polishers, planers, and general labourers.

The author concludes that all foundry workers run the risk of developing silicosis and that they should all, therefore, be eligible for industrial compensation in respect of this condition.

[It is difficult in the absence of radiographic illustration to compare these findings with those of other workers. 
The figure of $15 \%$ in the first stage agrees closely with the $17 \%$ of foundry workers found by McLaughlin and others (Industrial Lung Diseases of Iron and Steel Foundry Workers, London, 1950) to have fibrosis. The Belgian study confirms the main finding of the above report, namely, that all workers in iron and steel foundries run the risk of contracting silicosis.] John Pemberton.

Silicatosis of a Micronodular Type among Women Employed in Glaze Spraying on Metal Objects. TroISI, F. M. (1952). Indust Med. \& Surg., 21, 47.

The author describes 4 cases in which radiological abnormalities were discovered in the lungs of women exposed to enamel dust containing only 1 to $2 \%$ free silica, the rest being silicates. There was no disability. It is concluded that silicates are capable of producing pulmonary fibrosis, the radiographs being described as showing reticulation with micronodulation. [Reproductions of the radiographs are given, but are too small to show the precise nature of the abnormalities.]

C. M. Fletcher.

\section{GENERAL}

The Effect of Silicosis on the Cardiovascular System. Crepet, M., Palu, C. D., and Gargano, G. (1951). Arch. Inst. cardiol. Mex., 21, 178.

The effect of silicosis on the cardiovascular system has been assessed in 350 patients, who were classified in 3 stages : 96 had " early " disease and 142 had " advanced " disease. The methods of study included clinical and electrocardiographic examinations and estimation of effort tolerance, circulation time, and venous pressure. The results confirm those of other workers that cardiac involvement occurs only in the advanced stages of the disease, except that the incidence of cor pulmonale was less than that usually found.

A. J. Thomas.

Acoustic Trauma in Aircraft Maintenance Workers. GuILD, E. (1951). J. Aviat. Med., 22, 477.

Pure-tone audiograms for 11 different frequencies were determined in the following 4 groups of workers : mechanics concerned with conventional-type aircraft, mechanics dealing with jet engines, pilots with considerable flying experience, and personnel experiencing engine noise only as a background. Air-conduction studies were supplemented by bone-conduction studies in those subjects showing significant loss of acuity. The groups were roughly similar in size, age distribution, and duration of exposure, except that few pilots were less than 30 years of age.

For subjects below the age of 25 there was little over-all difference between the groups. At intermediate ages all groups showed diminished acuity to the higher frequencies, but the 2 groups of mechanics had a lower average auditory acuity than the normal, and this loss was more marked in mechanics and pilots working with jet engines than in those dealing with conventional-type aircraft. The differences tended to disappear with increasing age, but defects appeared earlier and were more marked in those subjected to noise. Subjects over 34 exhibited a comparable loss of acuity in all groups.

It is concluded that definite impairment of hearing may result from exposure to engine noise, and that jet engines impose a greater hazard than do conventional types. The marked loss of acuity found in the group of pilots might be due to their greater average age and to their longer exposure to noise.

P. Howard.

A Portable Ultramicroscope for the Determination of the Concentration of Submicroscopic Particles in the Air of Industrial Undertakings. BELKIN, E. S., and KOSENKO, A. (1951). Gigiena No. 8, 50.

For the ultramicroscopical estimation of dust particles of minute size in air the authors have made a portable apparatus in which the tube of the microscope passes through a hole in a closed box. Light from a lamp totally enclosed in a separate chamber of the box passes through a lens system and condenser to illuminate from the side a tube through which the contaminated air is passed below the microscope in such a way that it cannot deposit any dust in the box itself. By adjusting a diaphragm it is possible to arrange that at any one time no more than 4 or 5 dust particles appear in the field and can be counted before the current of air has passed on. [The apparatus would appear to be both convenient and effective.]

G. C. Pether.

"Back to Work". The Industrial Rehabilitation Units of the Ministry of Labour and National Service. Jones, J. A. L. Vaughan (1951). Brit. med. J., 2, 601.

The function of rehabilitation is " to restore the worker to industry, the citizen to society, and the man to himself ". There should be no clear-cut dividing line between medical and industrial rehabilitation, nor between industrial rehabilitation and resettlement. A residential industrial rehabilitation unit was set up at Egham, Surrey, in 1944, and since then other non-residential units have been set up at Birmingham, Bristol, Cardiff, Coventry, Edinburgh, Felling-on-Tyne, Glasgow, Hull, Leeds, Leicester, Long Eaton, Manchester, and Sheffield. Each caters for about 100 inmates, and their object is to restore the fitness of persons suffering from physical and mental disabilities which handicap them in getting and maintaining employment, to discover by observations and with medical advice the personal factors which may be impeding satisfactory settlement in employment, and the types of employment most likely to lead to permanent settlement.

Any person over the age of 16 is eligible to apply for a course of 12 weeks' duration, during which maintenance allowances are paid according to family circumstances. The facilities of these units include a gymnasium, workshops, and gardens, and these are used as necessary to meet the needs of each individual undergoing the course, which is under the direction of a medical officer, a vocational officer, an occupational supervisor, and a social worker. There have been 21,771 entrants, of whom 17,327 have completed the course recommended for placing in employment. $\quad K . M$. A. Perry. 